\title{
Advances in nonlinear vibration analysis of structures. Part-I. Beams
}

\author{
SUDHAKAR R MARUR
}

CSS Foundation, B4/4, Vaigai Nagar, Madurai 625 016, India

e-mail: smarur@iitiim.com

MS received 25 July 2000; revised 16 August 2000

\begin{abstract}
The development of nonlinear vibration formulations for beams in the literature can be seen to have gone through distinct phases-earlier continuum solutions, development of appropriate forms, extra-variational simplifications, debate and discussions, variationally correct formulations and finally applications. A review of work in each of these phases is very necessary in order to have a complete understanding of the process of evolution of this field. This paper attempts to achieve precisely this objective.
\end{abstract}

Keywords. Nonlinear vibrations; beams.

\section{Introduction}

The study of large amplitude vibration of simply supported beams can be traced to the work of Kreiger (1950), wherein the governing partial differential equations were reduced to ordinary differential equations and the solution was obtained in terms of elliptic functions using a one-term approximation. Similarly, Burgreen (1951) gave the solution for the large amplitude vibration problems of hinged beams based on the classical continuum approach. Srinivasan employed the Ritz-Galerkin technique to solve the governing nonlinear differential equation of dynamic equilibrium for free (Srinivasan 1965) and forced (Srinivasan 1966) vibration of simply supported beams and plates. Evensen (1968) extended the study for various boundary conditions using the perturbation method.

Ray \& Bert (1969) carried out experimental studies to verify the analytical solutions for the nonlinear vibrations of simply supported beam and compared the solution schemes such as the Assumed Space Mode (ASM), Assumed Time Mode (ATM) and RitzGalerkin methods and concluded that the latter two are better than the former. Pandalai \& Sathyamoorthy (1973) developed modal equations for the nonlinear vibrations of beams, plates, rings and shells using Lagrange's equation and highlighted the difference in the nature of the modal equations for beams and plates vis-á-vis rings and shells. 
Lou \& Sikarskie (1975) employed form-function approximations to study the nonlinear forced vibrations of buckled beam. Rehfield (1975) used an approximate method for nonlinear vibration problems with material nonlinear effects for various boundary conditions.

In the context of finite element solutions, Mallett \& Marcal (1968) proposed a scheme for writing the strain energy in a systematic way, known as 'appropriate form', containing three symmetric matrices - linear matrix $K$, nonlinear matrices $N_{1}$ and $N_{2}$, and also expressed equilibrium and linear incremental equations using these matrices. Rajasekaran \& Murray (1973) in their seminal paper presented an exact procedure/expression for deriving these matrices (proposed by Mallett \& Marcal 1968) for various elements in an elegant manner. Chen \& Huang (1986) extended the appropriate forms to the potential energy due to external loads also, as the work done by the external loads depend on the nodal degrees of freedom in the case of large deformation problems.

Reddy (1979) presented a review of the formulations of the 1970s related to structural vibrations. Sathyamoorthy (1982) compiled the work on classical methods for the analysis of beams with material, geometric and other types of nonlinearities and also on finite element analysis of nonlinear beams under static and dynamic loads. Another survey of work on shear deformation theories, finite elements and buckling (Kapania \& Raciti 1989a), along with those on free, forced, linear, nonlinear vibrations and wave propagation etc., with reference to laminated structures (Kapania \& Raciti 1989b) was reported.

Mei $(1972,1973)$ presented the finite element formulations for large amplitude vibrations of beams and plates. In all his work, the axial deformation was neglected and the average axial force was assumed to be a constant over the element length. Rao et al (1976) also studied the nonlinear vibrations of beams and plates and of beams with shear deformation and rotatory inertia. In these formulations, the axial deformation was not considered and the nonlinear strain-displacement relationship was linearized. Later, Raju et al (1976) studied the large amplitude vibration problem of beams and plates using Rayleigh-Ritz method by incorporating the inplane deformation as well as inertia, which were absent in the earlier studies, and also by retaining the equivalent linearization function.

Prathap (1977) contested the linearization procedure, inadequate interpretation of $\omega$ and also the conclusion made by Raju et al (1976) that 'the inclusion of inplane terms is insignificant'. Prathap \& Varadan (1978) studied the nonlinear vibrations of simply supported beams using the actual nonlinear equilibrium equations, exact nonlinear expression for curvature and the nonlinearity arising out of axial force. Also, they proposed criteria for definition of the degree of nonlinearity.

Later, the effect of neglect of axial displacement of a beam and of the premise to consider the load-displacement relationship as a linear one while deriving the equation of conservation of energy (Szilard 1978) has been demonstrated by Prathap (1980) using an 'one-term approximation' for a simply supported beam. The infeasibility of formulating a Ritz-type finite element, without incorporating longitudinal degree of freedom was then established by Prathap \& Bhashyam (1980).

Sarma \& Varadan (1982) brought out the errors due to procedures such as equivalent linearization, substitution of inplane boundary conditions at element level rather than at system level and the use of different connotations for $\omega$, adopted by many earlier formulations (Mei 1972, 1973; Rao 1976). 
The debate on core issues of formulations such as the neglect of longitudinal displacement, equivalent linearization approximation, interpretation of radian frequency $\omega$ and the computation of inplane force etc. with reference to the work by Bhashyam $\&$ Prathap (1980) and Sarma \& Varadan (1982, 1983), can be seen in the publications of Mei (1984) and Raju \& Rao (1984).

Later, Mei (1986) criticized the new definition of criteria for the degree of nonlinearity proposed by Prathap \& Varadan (1978) and also questioned the validity of frequency solutions presented by Bhashyam \& Prathap (1980) and Sarma \& Varadan (1982, 1983).

As a sequel to the points raised by others (Mei 1984; Raju \& Rao 1984; Mei 1986), Sarma et al (1988) presented a Rayleigh-Ritz solution incorporating the inplane displacement and inertia, and captured the error made in an earlier formulation (Raju et al 1976) due to the equivalent linearization approximation. Also, they re-examined the Galerkin (Bhashyam and Prathap 1980), Lagrange-type (Sarma \& Varadan 1983), Ritz (Sarma \& Varadan 1984) finite element formulations and presented two mixed finite element formulations to critically analyse various assumptions employed earlier for the simply supported beam vibration problem.

Dumir \& Bhaskar (1988) traced the errors in the nonlinear finite element formulations of beam and plate vibrations to the presence of a linearizing function in the strain energy evaluation and ascertained the magnitude of error involved due to this function.

Singh et al (1990a) derived frequency ratios from the equation of motion, energy balance equation and perturbation method along with the Ritz-Galerkin solution obtained from the following four possible combinations - with/without axial displacement and with/without linearization approximations. They observed that a formulation without axial displacement but with linearization and simple harmonics assumption would yield the same nonlinear frequencies as those of methods (such as Ritz-Galerkin, perturbation etc.) with axial displacement but without linearization and harmonic oscillation assumptions.

Subsequently, Singh et al (1990b) reported a formulation for the nonlinear free vibration of beams, wherein the dynamic finite element matrix equations were reduced to a scalar equation (using the converged mode shape), which was then solved using direct numerical integration and concluded that the axial displacements cannot be neglected in any nonlinear vibration analysis.

Bhashyam \& Prathap (1980) proposed a Galerkin finite element method for the large amplitude vibration of beams while Sarma \& Varadan (1983) published a Lagrange-type finite element formulation for the nonlinear vibration of immovably supported beams. Ritz type finite element formulations for the nonlinear vibration studies of classical beam (Sarma \& Varadan 1984) and Timoshenko beam (Sarma \& Varadan 1985) have also been reported.

A hybrid approach using both the finite element and perturbation procedure has been proposed for the vibration studies of nonlinear structures by Padovan (1980).

Reddy \& Singh (1981) published a total potential energy based traditional element and a Reissner-type variational functional based mixed finite element, with $u, w$ and $M_{x}$ as dependent variables for the study of nonlinear vibration of beams and shallow arches, considering both the transverse shear and rotatory inertia effects.

Heyliger \& Reddy (1988) presented a higher order theory with $C^{1}$ element formulation for the static and linear/nonlinear vibration studies of rectangular beams in which they 
explored the effects of inplane inertia and slenderness ratio on the nonlinear frequency of beams with various boundary conditions.

Kapania \& Raciti (1989c) proposed a two-noded Timoshenko beam element with 10 degrees of freedom per node to study the nonlinear vibrations of symmetrically and unsymmetrically laminated composite beams by employing the perturbation method.

Singh et al (1991) later studied the large-amplitude vibration problem of unsymmetrically laminated beams based on classical, first-order and higher-order formulations by using the numerical integration technique introduced earlier (Singh et al 1990b).

Various types of solutions to the nonlinear equation of motion such as Galerkin, harmonic balance method and simple harmonic oscillations based method were proposed and analysed by Pillai \& Rao (1992) while solutions by the method of multiple scales and ultra-spherical polynomial approximation method have been suggested by Srirangarajan (1994). Shi \& Mei (1996) proposed a finite element time domain modal formulation for the large amplitude free vibration analysis of beams and plates.

\section{Distinct phases of development}

The complete development of nonlinear vibration theory of beams is presented topic-wise in tables 1 and 2. While table 1 presents the earlier literature with continuum solution, the important phase of development of appropriate forms with first and second-degree nonlinear matrices is given in table 2a. Various reviews covering the 1970s and 80s are tabulated in table $2 \mathrm{~b}$.

Modelling the nonlinear vibration problems using finite elements, albeit with a couple of extra-variational simplifications (table 2c), stirred the proverbial hornet's nest. A series of papers on these issues, starting from 1977 is presented in table $2 \mathrm{~d}$.

Variationally correct formulations appeared in the literature from the 1980s (table 2e) and the applications of this area to problems such as composites etc. are presented in table 2f.

Table 1. Earlier continuum solutions.

\begin{tabular}{|c|c|c|}
\hline Type of solution & Author(s) & Year \\
\hline $\begin{array}{l}\text { Elliptic functions one-term } \\
\text { approximation }\end{array}$ & Kreiger & 1950 \\
\hline Classical continuum approach & Burgreen & 1951 \\
\hline Ritz-Galerkin technique & Srinivasan & 1965,1966 \\
\hline Perturbation method & Evensen & 1968 \\
\hline $\begin{array}{l}\text { Experimental, ASM, ATM and } \\
\text { Ritz-Galerkin }\end{array}$ & Ray \& Bert & 1969 \\
\hline Lagrange's equation & $\begin{array}{l}\text { Pandalai \& } \\
\text { Sathyamoorthy }\end{array}$ & 1973 \\
\hline Form-function approximation & Lou \& Sikarskie & 1975 \\
\hline
\end{tabular}


Table 2. Distinct phases of development.

Details

Author(s)

Year

(a) Development of appropriate forms

Appropriate form

First and second degree nonlinear matrices

Appropriate forms for energy

due to external loads

(b) Review papers

Structural vibrations

Nonlinear analysis of beams

Studies on laminated beams

(c) Extra-variational simplifications (EVS)

Neglect of inplane displacement

Quasi-linearisation

Quasi-linearisation with inplane displacement

(d) Debate and discussions on EVS

On quasi-linearisation procedure

Effect of neglect of axial displacement

Inplane displacement for Ritz type formulation

Errors due to various simplifications

Discussion on EVS

Discussion on definition criteria

for nonlinearity of

Prathap \& Varadan (1978)

Summary of various methods and errors due to EVS

Errors due to quasi-linearisation

Debate on EVS

(e) Variationally correct formulations

Galerkin finite element

Lagrange-type finite element

Ritz f.e. - classical beams

Ritz f.e. - Timoshenko beams

(f) Applications

Perturbation solution with finite element

Higher-order mixed finite element

Higher-order $C^{1}$ element

Composite beam with 10 d.o.f. per node

Nonlinear vibrations of composite beam

Comparison of solutions

Polynomial approximation

Time-domain model
Mallett \& Marcal 1968

Rajasekaran \& Murray 1973

Chen \& Huang 1986

Reddy 1979

Sathyamoorthy 1982a, 1982b

Kapania \& Raciti 1989a, 1989b

Mei

Rao et al

Raju et al

1972, 1973a, 1973b

1976a, 1976b

1976

1977

$\begin{array}{ll}\text { Prathap } & 1980 \\ \text { Prathap \& Bhashyam } & 1980\end{array}$

Sarma \& Varadan 1982

Mei 1984

Raju \& Rao 1984

Mei 1986

Sarma et al $\quad 1988$

Dumir \& Bhaskar $\quad 1988$

Singh et al 1990

Bhashyam \& Prathap 1980

Sarma \& Varadan 1983

Sarma \& Varadan $\quad 1984$

Sarma \& Varadan $\quad 1985$

Padovan $\quad 1980$

Reddy \& Singh $\quad 1981$

Heyliger \& Reddy 1988

Kapania \& Raciti $\quad 1989$ c

Singh et al 1991

Pillai \& Rao 1992

Srirangarajan $\quad 1994$

Shi \& Mei 1996 


\section{Conclusions}

It can be concluded that the most significant phase has been that of the development of appropriate forms and of variationally correct formulations and perhaps the crucial phase was that of debate and discussions. This study, it is hoped, will serve the purpose of providing a state-of-the-art overview of the nonlinear vibration theory of beams.

\section{References}

Bhashyam G R, Prathap G 1980 Galerkin finite element method for nonlinear beam vibrations. $J$. Sound Vib. 72: 191-203

Burgreen D 1951 Free vibrations of a pin-ended column with constant distance between pin ends. $J$. Appl. Mech., ASME 18: 135-139

Chen J S, Huang T 1986 Appropriate forms in nonlinear analysis. J. Eng. Mech. Div., ASCE 111: $1215-1226$

Dumir P C, Bhaskar A 1988 Some erroneous finite element formulations of nonlinear vibrations of beams and plates. J. Sound Vib. 123: 517-527

Evensen D A 1968 Nonlinear vibrations of beams with various boundary conditions. AIAA J. 6: 370-372

Heyliger P R, Reddy J N 1988 A higher order beam finite element for bending and vibration problems. J. Sound Vib. 126: 309-326

Kapania R K, Raciti S 1989a Recent advances in analysis of laminated beams and plates, Part I: Shear effects and buckling. AIAA J. 27: 923-934

Kapania R K, Raciti S 1989b Recent advances in analysis of laminated beams and plates, Part II: Vibrations and wave propagation. AIAA J. 27: 935-946

Kapania R K, Raciti S 1989c Nonlinear vibrations of unsymmetrically laminated beams. AIAA J. 27: $201-210$

Kreiger S W 1950 The effect of an axial force on the vibration of hinged bars. J. Appl. Mech., ASME 17: 35-36

Lou C L, Sikarskie D L 1975 Nonlinear vibration of beams using a form-function approximation. $J$. Appl. Mech., ASME 42: 209-214

Mallett R H, Marcal P V 1968 Finite element analysis of nonlinear structures. J. Struct. Div., ASCE 94: 2081-2105

Mei C 1972 Nonlinear vibrations of beams by matrix displacement method. AIAA J. 10: 355-357

Mei C 1973a Finite element displacement method for large amplitude free flexural vibrations of beams and plates. Comput. Struct. 3: 163-174

Mei C 1973b Finite element analysis of nonlinear vibrations of beam columns. AIAA J. 11: 115-117

Mei C 1984 Comments on "Lagrange-type formulation for finite element analysis of nonlinear beam vibrations" J. Sound Vib. 94: 445-452

Mei C 1986 Discussions of finite element formulations of nonlinear beam vibrations. Comput. Struct. 22: 83-85

Padovan J 1980 Nonlinear vibrations of general structures. J. Sound Vib. 72: 427-441

Pandalai K A V, Sathyamoorthy M 1973 On the modal equations of large amplitude flexural vibration of beams, plates, rings and shells. Int. J. Nonlinear Mech. 8: 213-218

Pillai S R R, Rao B N 1992 On nonlinear free vibrations of simply supported uniform beams. $J$. Sound Vib. 159: 527-531

Prathap G 1977 Comments on "Effect on longitudinal or inplane deformation and inertia on the large amplitude flexural vibrations of slender beams and thin plates". J. Sound Vib. 55: 308-311

Prathap G 1980 A discussion on "A hybrid, finite element-finite difference approach to simplified large deflection analysis of structures" by Rudolph Szilard. Comput. Struct. 11: 251-253

Prathap G, Bhashyam G R 1980 Comments on nonlinear vibrations of immovably supported beams by finite-element method. AIAA J. 18: 733-734 
Prathap G, Varadan T K 1978 The large amplitude vibration of hinged beams. Comput. Struct. 9: 219-222

Rajasekaran S, Murray D W 1973 Incremental finite element matrices. J. Struct. Div., ASCE 99: 2423-2437

Raju I S, Rao G V, Raju K K 1976 Effect of longitudinal or inplane deformation and inertia on the large amplitude flexural vibrations of slender beams and thin plates. J. Sound Vib. 49: 415-422

Raju K K, Rao G V 1984 A note on large amplitude vibrations. Comput. Struct. 18: 1189-1191

Rao G V, Raju K K, Raju I S 1976a Finite element formulation for the large amplitude free vibrations of beams and orthotropic plates. Comput. Struct. 6: 169-172

Rao G V, Raju I S, Raju K K 1976b Nonlinear vibrations of beams considering shear deformation and rotary inertia. AIAA J. 14: 685-687

Ray J D, Bert C W 1969 Nonlinear vibrations of a beam with pinned ends. J. Eng. Ind., ASME 91: 977-1004

Reddy J N 1979 Finite element modelling of structural vibrations: A review of recent advances. Shock Vib. Dig. 11: 25-39

Reddy J N, Singh I R 1981 Large deflections and large-amplitude free vibrations of straight and curved beams. Int. J. Numer. Methods Eng. 17: 829-852

Rehfield L W 1975 A simple, approximate method for analysing nonlinear free vibrations of elastic structures. J. Appl. Mech., ASME 42: 509-511

Sarma B S, Varadan T K 1982 Certain discussions in the finite element formulation of nonlinear vibration analysis. Comput. Struct. 15: 643-646

Sarma B S, Varadan T K 1983 Lagrange-type formulation for finite element analysis of nonlinear beam vibrations. J. Sound Vib. 86: 61-70

Sarma B S, Varadan T K 1984 Ritz finite element approach to nonlinear vibrations of beams. Int. J. Numer. Methods Eng. 20: 353-367

Sarma B S, Varadan T K 1985 Ritz finite element approach to nonlinear vibrations of a Timoshenko beam. Commun. Appl. Numer. Methods 1: 23-32

Sarma B S, Varadan T K, Prathap G 1988 On various formulations of large amplitude free vibrations of beams. Comput. Struct. 29: 959-966

Sathyamoorthy M 1982a Nonlinear analysis of beams, Part-I: A survey of recent advances. Shock Vib. Dig 14: 19-35

Sathyamoorthy M 1982b Nonlinear analysis of beams, Part-II: Finite-element methods. Shock Vib. Dig. 14: 7-18

Shi Y, Mei C 1996 A finite element time domain model formulation for large amplitude free vibrations of beams and plates. J. Sound Vib. 193: 453-465

Singh G, Sharma A K, Rao G V 1990a Large-amplitude free vibrations of beams - A discussion on various formulations and assumptions. J. Sound Vib. 142: 77-85

Singh G, Rao G V, Iyengar N G R 1990b Reinvestigation of large amplitude free vibrations of beams using finite elements. J. Sound Vib. 143: 351-355

Singh G, Rao G V, Iyengar N G R 1991 Analysis of the nonlinear vibrations of unsymmetrically laminated composite beams. AIAA J. 29: 1727-1735

Srinivasan A V 1965 Large amplitude free oscillations of beams and plates. AIAA J. 3: 1951-1953

Srinivasan A V 1966 Nonlinear vibrations of beams and plates. Int. J. Nonlinear Mech. 1: 179-191

Srirangarajan H R 1994 Nonlinear free vibrations of uniform beams. J. Sound Vib. 175: 425-427

Szilard R 1978 A hybrid, finite element-finite difference approach to simplified large deflection analysis of structures. Comput. Struct. 9: 341-350 